\title{
SOBRE EL DERECHO PROCESAL EN EL SIGLO XXI
}

\author{
Héctor Enrique Peñaranda Valbuena ${ }^{1}$ \\ Olga Quintero de Peñaranda ${ }^{2}$ \\ Héctor Ramón Peñaranda Quintero ${ }^{3}$ \\ Universidad del Zulia, Venezuela \\ Mercedes Peñaranda ${ }^{4}$ \\ Universidad Rafael Belloso Chacín, Venezuela
}

\begin{abstract}
Resumen.- La enseñanza del Derecho Procesal en el siglo XXI ha propiciado que en la doctrina un gran número de autores se sientan motivados por estudiar, sobre todo, las razones que argumentan la necesidad de que exista una doctrina común en torno a esta rama del Derecho, útil desde el punto de vista científico y pedagógico, formulando los conceptos ordenadores de los diferentes procesos. De lo expuesto anteriormente consideramos de manera integral que esta disciplina se define como la ciencia que estudia y regula la actividad coordinada del juzgador y las partes con el fin de resolver los conflictos jurídicos entre ellos, mediante la aplicación vinculatoria de las normas de Derecho. Siendo su función primordial no sólo servir sino el hacer eficaz el derecho material.
\end{abstract}

Palabras clave.- proceso, ley, procesal, derecho

\begin{abstract}
The education of the Procedural Right in the 21st century has caused that in the doctrine a great number of authors feels motivated to study, mainly, the reasons that argue the necessity that a common doctrine around this branch of the Right exists, useful from the scientific and pedagogical point of view, formulating the concepts computers of the different processes. Of the exposed thing previously we considered of integral way that this discipline is defined as the science that studies and regulates the coordinated activity of the judge and the parts with the purpose of to solve the legal conflicts among them, by means of the application of the norms of Right. Being its fundamental function not only to serve but effective doing the material right.
\end{abstract}

\footnotetext{
${ }^{1}$ Abogado, Doctor en Derecho, Juez Emérito, Profesor de Postgrado en la Maestría de Derecho Procesal Civil y Profesor de Teoría General del Proceso de pregrado de la Escuela de Derecho de la Facultad de Ciencias Jurídicas y Políticas de la Universidad del Zulia

${ }^{2}$ Abogada, Doctora en Derecho, Magíster en Derecho Procesal Civil, Profesora de Postgrado en la Maestría de Derecho Procesal Civil y Profesora de Teoría General del Proceso y Derecho Procesal Civil II, de la Escuela de Derecho de la Facultad de Ciencias Jurídicas y Políticas de la Universidad del Zulia

${ }^{3}$ Abogado, Doctor en Derecho, Magíster en Derecho Procesal Civil, Magíster en Gerencia Tributaria, Magíster en Psicoanálisis, Especialista en Derecho de la Niñez y Adolescencia, Especialista en Educación y Pensamiento de la Infancia, Juez Titular del Tribunal de Protección de Niños, Niñas y Adolescentes del Estado Zulia, Profesor de Postgrado en la Especialización en Derecho de la Niñez y Adolescencia y Profesor de Derecho de Personas y de Familia de la Escuela de Derecho de la Facultad de Ciencias Jurídicas y Políticas de la Universidad del Zulia.

${ }^{4}$ Abogada, Doctora en Derecho, Magíster en Derecho Procesal Civil, Profesora de Derecho Romano de la Escuela de Derecho de la Facultad de Ciencias Jurídicas y Políticas de la Universidad Rafael Belloso Chacín
} 
Key words.- process, law, procedural, law

\section{INTRODUCCIÓN}

La idea de conformar una teoría general unitaria del Derecho Procesal ha sido enjuiciada desde sus inicios por algunos autores estudiosos del tema, por lo que para entender la naturaleza del conflicto en cuestión, se impone realizar una breve ubicación temporal del nacimiento y evolución del problema teórico, que sienta sus bases en los primeros momentos del surgimiento del Derecho Procesal como ciencia.

Existen algunos autores que, de alguna manera, ubican el origen de la civilización en el origen mismo del proceso, sin embargo habría de pasar mucho tiempo para que los estudios acerca de éste evolucionaran hasta la autonomía de una verdadera ciencia, de allí que pueda afirmarse que el Derecho Procesal, como verdadera disciplina científica, es una rama de creación moderna.

La autonomía del Derecho Procesal atravesó por varias etapas, remontando sus inicios a los siglos XVI al XVIII, donde en las universidades europeas y americanas se enseñaba exclusivamente Derecho Romano.

Un movimiento paralelo, que luego se denominó Práctica Forense, comenzó a preocuparse por la forma en que se desenvolvían los procedimientos ante los tribunales para ser utilizado por los operadores jurídicos al momento de litigar, es decir, solo se describía la realidad imperante, sin ningún tipo de proyección teórico-sistemática.

El siglo XIX marcó la entrada de la práctica forense a las universidades europeas con un nuevo estilo, a partir de los códigos napoleónicos, de la exégesis como método de interpretación y de enseñanza, de los grandes comentarios a esos códigos, de la incorporación de estudios sobre organización judicial, competencia de los tribunales y procedimiento. Este nuevo método, que sustituyó progresivamente al eminentemente práctico, es denominado por la doctrina como procedimentalismo, donde no existe una verdadera ciencia jurídica procesal, pero se prepara el camino hacia ella con la obra de los comentaristas.

La verdadera autonomía del Derecho Procesal llegó de manos de los alemanes 
los que por no tener un código que comentar, se vieron impulsados a crear las bases científicas para elaborar su propio código y no la explicación de uno ya promulgado, destacándose en esta labor y en la evolución del concepto de acción procesal Bernard Windscheid, Theodor Muther, Oskar Von Bullow, Adolf Wach; no obstante, a Giuseppe Chiovenda, se le reconoce la paternidad del Derecho Procesal ya que planteó que "la acción es un poder que corresponde frente al adversario, respecto del cual se produce el efecto jurídico de la actuación de la ley. El adversario no está obligado a ninguna cosa frente a este poder; está, simplemente, sujeto a él. La acción se agota en su ejercicio, sin que el adversario pueda hacer nada para impedirla, ni para satisfacerla. Tiene naturaleza privada o pública, según que la voluntad de la ley cuya actuación produce tenga naturaleza privada o pública". Los estudios procesales estaban estrechamente vinculados al concepto de acción, mientras la acción fue un mero elemento del derecho subjetivo violado, no era concebible un Derecho Procesal autónomo.

Otro momento importante en la evolución del Derecho Procesal como una disciplina científica lo representó la obra del alemán Oskar von BÜLLOW (1964), el que con sus estudios logró separar conceptualmente la relación jurídica que tiene lugar en el proceso entre el tribunal y las partes, de la relación jurídica de derecho material que le precede. Esta concepción fue muy importante en el proceso de independencia del Derecho Procesal del Derecho Privado.

La evolución general de los estudios de esta rama culmina con la consideración de la jurisdicción como eje central. Acorde con ello, propone denominar a la rama "Derecho Jurisdiccional". Los antecedentes de este desarrollo se remontan a los inicios mismos de la ciencia procesal y permiten concluir que el proceso es un instrumento necesario para el cumplimiento de la función jurisdiccional.

De lo expuesto anteriormente consideramos de manera integral que esta disciplina se define como la ciencia que estudia y regula la actividad coordinada del juzgador y las partes con el fin de resolver los conflictos jurídicos entre ellos, mediante la aplicación vinculatoria de las normas de Derecho. Siendo su función primordial no sólo servir sino el hacer eficaz el derecho material.

\section{EL DERECHO PROCESAL}

En el Derecho Procesal hay tres grandes conceptos: LA JURISDICCION, LA ACCION Y EL PROCESO. Estos tres grandes conceptos son la parte central, directriz de la Teoría General del Proceso. Porque la Teoría General del Proceso estudia los conceptos, los principios y las instituciones formativas de la Ciencia Procesal.

Podríamos ensayar una definición de Derecho Procesal. 
Qué es en realidad, el Derecho Procesal?

Es el estudio de las normas procesales que vinculan a las partes: actor y demandado y al Juez con el Estado, e indican la conducta de éstos dentro del proceso para la actuación de la voluntad de la Ley.

Para Palacio (1968: p 13):

"La disciplina que tradicionalmente se conoce bajo la denominación de derecho procesal, estudia por una parte el conjunto de actividades que tienen lugar cuando se somete a la decisión de un tribunal judicial o arbitral la solución de determinada clase de conflictos suscitados entre dos o más personas (partes), o cuando se requiere la intervención de un tribunal judicial para que constituya, integre o acuerde eficacia a determinada relación o situación jurídica".

El procesalista Humberto Cuenca (1974), dice que el Derecho Procesal es un conjunto de normas que regulan el proceso.

Esto significa, por ejemplo, que cuando se presenta una demanda, la presentamos a un Tribunal, a un Organo Jurisdiccional, el Estado revisa la demanda y ordena citar al demandado; éste viene a contestar la demanda; entonces, el Derecho Procesal regula la conducta de las partes dentro del proceso y determina el procedimiento por medio del cual se va a ejercitar el derecho y el Estado la forma de decidir, según la voluntad de la Ley. Para establecer el derecho positivo, el Juez aplica complementariamente la Ley al hecho histórico, o sea al libelo de la demanda y a su contestación, pruebas, etc.

\section{NATURALEZA DEL DERECHO PROCESAL}

Es un Derecho que está en el campo del Derecho Público; porque cuando yo demando, el Estado recibe la demanda, se crea una relación pública con el Estado; las partes se someten al Estado; se crea una sujeción con el poder monopólico del Estado para que éste pueda mantener la paz con justicia.

Esto no significa que las normas procesales sean todas de orden público.

Hay normas que son de orden público y hay otras que son derogables; por ejemplo: no se puede cambiar el procedimiento que trae el Código de Procedimiento Civil, sino que tiene que someterse a las normas del Estado; otras sí son derogables a voluntad de las partes; por ejemplo: las partes en un proceso pueden suspender el procedimiento (a solicitud de las partes y de mutuo acuerdo), acortar el lapso para la contestación de la demanda, como cuando en un juicio ordinario la parte desea abreviar y renunciar, de acuerdo con la otra parte, porque se da en interés de la parte; pero no ocurre lo mismo en un juicio de divorcio; porque dichas normas que regulan el divorcio son de orden público y hay que dejar correr el lapso correspondiente. 


\section{CARACTERISTICAS DEL DERECHO PROCESAL}

1) Es un Derecho formal: Porque el Derecho Procesal tiene las formas y medios a través de los cuales las partes se comunican con el Estado. Por ejemplo, con relación al modo de intentar una demanda, están las formas cómo actuar, cómo se contesta, cómo se promueven las pruebas y su correspondiente evacuación, etc.; o sea, se nos dice la forma, la manera de actuar en el proceso. El actor demanda y pide al Juez; el demandado tiene su forma y tiempo de oponerse a lo que pide el actor; todo en su oportunidad, y luego al Estado le toca decidir lo que se le está pidiendo.

2) Es un Derecho instrumental: Viene de los Civilistas; se decía que no era una Ciencia, sino un conjunto de reglas a través de las cuales el derecho material hallaba su fin, o sea, que el Derecho Procesal no es fin en sí mismo, sino que sirve de medio, de instrumento, para lograr la observancia del derecho substancial.

El procesalista Jaime Guasp (1977) afirma que el derecho material es el instrumento a través del cual el Derecho Procesal mantiene la paz con justicia. O sea, el Derecho Procesal usa el derecho material para mantener la paz con justicia.

El Derecho Civil no es más importante que el Derecho Procesal; todos son iguales y necesarios, se complementan para mantener el orden jurídico.

3) Es un Derecho autónomo: Porque tiene sus propias reglas, principios y conceptos; y lo diferencia de las demás Ramas del Derecho. Ej: el Derecho Procesal tiene un Principio de que las partes son iguales ante el Estado; igualmente, el Principio de Contradicción o Derecho de Defensa, el de la Cosa Juzgada, son Principios propios del Derecho Procesal.

4) Es un Derecho imperativo: Porque las decisiones que emanan del Estado son de obligatorio cumplimiento y se traducen en ejecución forzosa e imponen la voluntad del Estado frente a los particulares. Ej: si se dicta una sentencia, mediante la fuerza del Derecho, los particulares (en el caso concreto), tienen que cumplirla; o sea, el Estado impone su voluntad.

\section{MÉTODO}

¿Qué método vamos a usar en el Derecho Procesal?

Con una demanda se está proponiendo un conflicto de intereses contra el demandado; el juicio es como una guerra. Para que no haya desorden social, el Congreso crea las leyes; pero si una persona me quita mi propiedad, y este conflicto 
lo llevo a un Tribunal, al Estado, es como un juego de ajedrez, que los dos, actor y demandado quieren ganar. Se plantea al juez una lucha y hay que usar un método dialéctico. Se ha dicho que el método del Derecho Procesal es un método de investigación para el conocimiento científico del orden jurídico procesal.

El actor plantea su tesis: echa el cuento en la demanda; el demandado cuando contesta plantea la antítesis; y al final el Estado, a través del Juez, sentencia, que es la síntesis, la decisión del conflicto; por eso las partes se subordinan al Estado en una forma sustitutiva del derecho de defensa privado.

Por lo tanto, el método dialéctico es una lucha de intereses que se lleva al Estado para resolverlo. En el Derecho Procesal las instituciones se transforman y se enriquecen a cada instante con nuevos contenidos, como toda la Ciencia jurldica, el Procesal está en constante transformación. Y como la misión del proceso es desarrollar y avanzar, así también la del Derecho Procesal es la adquisición de nuevas categorías para una realización más humana y menos teórica de la justicia. El proceso es el desenvolvimiento gradual de una lucha de táctica y estrategia para obtener, finalmente, una sentencia favorable; es el debate entre dos posiciones egoístas, una lucha de contrarios entre el demandante y el demandado, reflejo de las contradicciones de clase del mundo occidental.

Hasta fines del siglo XIX el proceso había sido considerado como la técnica para hacer efectivas las soluciones del derecho privado. Los investigadores alemanes Windscheid, Muther, Bullow, Wach y otros, realizaron una gran investigación para descubrir nuevos principios, clasificaciones, que dieran al Derecho Procesal una categoría científica. Los prácticos del Derecho Francés y del Español, en pugna con los teóricos alemanes, alegaban la inutilidad de estas contradicciones; y en la pugna triunfó la dogmática procesal.

Entonces, el Método Científico se los voy a explicar con un ejemplo: Cuando se introduce la demanda, le cuento un hecho histórico al Juez, y le pido aplique el Derecho. El Juez, ve las dos verdades: la del actor en su libelo de demanda y la del demandado en su contestación dada a la demanda incoada en su contra; qué hace el Juez para aplicar el Derecho? Fija la inteligencia cuando va leyendo en esa realidad jurídica: el hecho específico real, y sacando deducciones intelectivas: mira los hechos; como las partes tienen que probar lo alegado, el Juez hace un rastreo histórico del proceso y saca datos racionales de lo que está leyendo y finalmente saca la especie lógica: la decisión de ese estado comparativo, o sea la sentencia.

\section{FUENTES DEL DERECHO PROCESAL}

Siguiendo a Podetti (1956), se pueden dividir en:

Fuentes Vinculantes y Fuentes No Vinculantes. 


\section{Fuentes Vinculantes:}

Son aquellas de obligatorio cumplimiento para el Juez y cuando un Juez actúa contra ello, actúa contra legem, pues está obligado a acatarlas; ellas son:

1) La Constitución Nacional: De acuerdo con Kelsen, citado por Podetti (1956), está en la pirámide arriba. El Código de Procedimiento Civil en su artículo 20, dice: "Cuando la Ley vigente, cuya aplicación se pida, colidiere con alguna disposición Constitucional, los Jueces aplicarán ésta con preferencia". En la Constitución encontramos los principios procesales fundamentales, que Couture (1976) denominó las garantías constitucionales del proceso, y también encontramos en la Constitución ciertas normas atinentes a la organización judicial.

En la Constitución Nacional encontramos las garantías constitucionales del proceso civil, entre éllas tenemos: los art. 51 y 49 de la Constitución Nacional, que reconoce el derecho de petición ante cualquier funcionario público y el derecho a la defensa, como derecho inviolable en todo estado y grado del proceso. El art. 49 ordinal 4 , de la Constitución Nacional establece que nadie puede ser juzgado sino por sus jueces naturales, ni condenado a sufrir pena que no esté establecida por ley preexistente. El artículo 49, Ordinal 7 eiusdem, que establece el principio de la Cosa Juzgada, según el cual nadie puede ser sometido a juicio por los mismos hechos en virtud de los cuales hubiere sido juzgado anteriormente.

2) Los Tratados Internacionales: En todos los casos en que Venezuela haya firmado Tratados Públicos y se presente conflicto entre una de las partes, se aplica el Tratado preferentemente a las leyes nacionales. La antigua Corte Suprema de Justicia ha dicho que en todo caso, al ser aprobado cualquier Tratado por el Congreso, son leyes nacionales. Los Tratados Internacionales prevalecen después de la Constitución Nacional, en los casos de aplicación del Derecho Internacional Privado sobre las demás Leyes de la República, (Art. 8 del Código de Procedimiento Civil y art. 8 de la Ley de Derecho Internacional Privado).

Entre los Tratados en materia procesal, tenemos: el Código de Bustamante, llamado también Código Internacional Privado, puesto en vigencia por la Convención de Derecho Internacional Privado celebrada en la Sexta Conferencia Panamericana en La Habana, el 20 de febrero de 1.928, suscrito por Venezuela. El Protocolo sobre Uniformidad del Régimen Legal de los Poderes, suscrito en Washington el 17 de febrero de 1.940, ratificado por Venezuela el 9 de octubre de 1.941. El Tratado de Extradición firmado entre Venezuela y los Estados Unidos de Norteamérica el 19 de enero de 1.922. El Protocolo sobre la Personalidad Jurídica de las Compañías Extranjeras; la Convención Interamericana sobre Exhortos o Cartas Rogatorias y otros más.

3) Sentencias de la Sala Constitucional del Tribunal Supremo de Justicia. (Art. 335 de la Constitución de la República Bolivariana de Venezuela).

4) Leyes Orgánicas y demás Leyes Nacionales: Que son el Código de Procedimiento Civil (que es la ley reglamentaria de las garantías de Justicia en la Constitución 
Nacional), artículos 40, 16, 15, 215, 346 ordinal 9 y 361 del Código de Procedimiento Civil; el Código Orgánico Procesal Penal, Código Orgánico Procesal del Trabajo, Ley Orgánica del Poder Judicial, las cuales desenvuelven los principios de la Constitución referentes a la organización de la justicia en Venezuela, con excepción del Tribunal Supremo de Justicia que tiene su propia Ley Orgánica; la Ley de Carrera Judicial, relacionada con la idoneidad, estabilidad e independencia de los jueces y las condiciones para su ingreso, permanencia y terminación en el ejercicio de la función judicial; la Ley de Abogados, priva sobre la general.

\section{Fuentes No Vinculantes:}

1) La Jurisprudencia: En la Ley de Indias era necesario que se mantuviera por 30 años una jurisprudencia. Hoy en día la Jurisprudencia es la sentencia que dictan los Tribunales y algunas mantiene a través de la Corte Suprema de Justicia, hoy Tribunal Supremo de Justicia, su uniformidad para mantener la integridad de la Ley. Las sentencias del Tribunal Supremo de Justicia, en sus distintas Salas, a excepción de la Sala Constitucional, no son vinculantes, sino en el caso concreto; ejemplo: si yo formalizo un Recurso de Casación en alguna de las Salas Civil o Social, y me lo declaran con lugar, el Juez de Reenvío no puede sentenciar de nuevo distinto a como ordenó la respectiva Sala; en este caso sí es vinculante.

2) La Doctrina: proviene desde Roma con la opinión de los grandes jurisconsultos. Actualmente se usa mediante la opinión de autores.

3) El Derecho Comparado: Cuando en el sistema positivo nuestro no existe una forma de aplicación concreta, el juez puede buscar una institución de otro Estado que se pudiera utilizar en Venezuela, para poder resolver el problema; puede usarse el Derecho Comparado para resolver el derecho nacional cuando no exista nada al respecto.

\section{PRINCIPIOS EXCLUSIVOS DEL DERECHO PROCESAL: DE DEMANDA, PRESENTACION, PRECLUSION, CELERIDAD, ECONOMIA PROCESAL, IGUALDAD, LEALTAD Y PROBIDAD, PUBLICIDAD, VERACIDAD}

\section{Principio de Demanda}

Según el cual: nemo iudex sine actore, ne procedat iudex ex officio. Este principio está consagrado en el Código de Procedimiento Civil cuando, en el artículo 11, se dice: que en materia civil, el juez no puede iniciar el proceso sino previa demanda de parte; tampoco puede el juez tener en cuenta hechos ni medios de prueba que no han sido aportados por las partes. Esto es lo que se conoce como Principio de Presentación, por el cual Quod non est in actis non est in mundo. De acuerdo a este Principio, el Juez debe resolver de acuerdo a lo que tienen las actas, las cuales le 
dan la verdad del proceso, porque el mundo del juez está en las actas procesales y éste debe resolver secundum allegata et probata, o sea, según lo alegado y probado en las actas del proceso. Este Principio como el anterior, están contenidos en el artículo 12 del Código de Procedimiento Civil, porque el Juez debe atenerse a lo alegado y probado en las actas del proceso, sin poder sacar elementos de convicción fuera de éstos, ni suplir excepciones ni argumentos de hechos no alegados ni probados.

\section{Principio de Preclusión:}

El desarrollo de la relación jurídica procesal se hace por estadios o períodos, por lo cual, el paso de un estadio al siguiente, supone la clausura del anterior, de tal forma, que los actos procesales cumplidos quedan firmes y no puede volverse sobre éllos. Es esto lo que constituye la preclusión, el efecto que tiene un estadio procesal de clausurar el anterior, impidiéndose la repetición de los actos procesales y creándose el progreso inmediato del proceso hasta su consecución con la sentencia.

Existe Preclusión por pérdida y por extinción.

Hay preclusión por PERDIDA de una facultad procesal, por falta de actividady por actividad extemporánea.

Hay falta de actividad, cuando no ejecutamos el acto procesal que la ley permite y se produce la preclusión de nuestra facultad procesal. Tal ocurre, por ejemplo, cuando dictada la sentencia, la parte perdidosa deja transcurrir el lapso para apelar. Se dice que precluye su facultad procesal por falta de ejercitación de su derecho subjetivo procesal de apelación.

Y hay preclusión por actividad extemporánea, cuando las partes ejercen su actividad antes o después del término o lapsos señalados por la ley. Por ejemplo, cuando ejercitamos la apelación después de vencido el lapso; o cuando lo hacemos antes de nacer el lapso. Esto último es muy frecuente actualmente en los Tribunales, porque de conformidad con el artículo 198 del Código de Procedimiento Civil, no se computará aquél en que se dicte la providencia o se verifique el acto que dé lugar a la apertura del lapso; de tal modo que si se dicta sentencia y la parte perdidosa apela el mismo día en que se dictó la sentencia, su actividad procesal es extemporánea, porque aún no había nacido el lapso para la apelación. Se dice que hay preclusión por actividad extemporánea.

Hay preclusión por extinción:

1. Por incompatibilidad. 2. Por eventualidad.

En el caso de incompatibilidad, consiste en la realización de un acto incompatible con el ejercicio de otro, lo cual ocasiona la preclusión del anterior. Así, citado el demandado y contestada la demanda al fondo, no puede oponer luego cuestiones previas, porque la contestación al fondo de la demanda ocasiona la preclusión por incompatibilidad de las cuestiones previas. Inversamente, si oponemos cuestiones 
previas, no podemos contestar al fondo la demanda, hasta tanto no sean resueltas las cuestiones previas, clausurándose dicho estadio en el desarrollo de la relación procesal y pasando inmediatamente después a la contestación al fondo de la demanda.

Hay preclusión por eventualidad, que viene a ser el llamado Principio de Eventualidad, cuando la parte no ejercita todos sus derechos y cargas procesales de una sola vez. Por ejemplo, de acuerdo con el Principio de Eventualidad, la parte actora debe alegar todas sus pretensiones en la demanda y el demandado a su vez, debe ejercer todas sus defensas de una sola vez en el orden legal. En ese sentido, permite el legislador que en el lapso para la contestación de la demanda, el demandado puede oponer cuestiones previas. Sin embargo, si la parte demandada alega una o dos cuestiones previas, cuando tenía otras más que oponer y alegar, ya después de ejercitado su derecho, no puede volverlo a hacer y debió oponer todas las defensas de una sola vez, porque de acuerdo al Principio de Consumación Procesal, una vez ejercida la facultad, queda agotada por consumación. Contestada la demanda, no puede el demandado solicitar una nueva oportunidad para agregar defensas o razones que olvidó; ni tampoco el actor agregar nuevas pretensiones y defensas que debió hacer al comienzo de la causa, debido a que la litis no puede ser modificada o alterada después de planteada, con nuevas pretensiones o defensas.

Después de visto el Principio de Preclusión, debemos señalar, que el llamado Principio de Economía Procesal comprende tanto el Principio de Preclusión, como el de Concentración y Acumulación Procesal.

Realmente, existe Economía Procesal a través del Principio de Preclusión, porque se impide la regresión del proceso y el cumplimiento de un estadio procesal, clausura el anterior, como se dijo. Hay Economía Procesal con el Principio de Concentración, que rige sobre todo en los juicios orales, por el cual los actos se pueden realizar concentradamente en una o en el menor número de audiencias o días de despacho posibles, tratando de realizarse todo en un solo acto; esto último corresponde también al llamado Principio de Eventualidad, porque eventualmente se acumulan todas las actuaciones necesarias para que el juez las analice en su oportunidad. $Y$ en la Acumulación Procesal se evita la proliferación de controversias. Ya veremos, que cuando existen causas que tengan conexión o que deban acumularse en razón de los sujetos, objeto o título, se acuerda acumularlas para evitar tanto su proliferación como que se dicten sentencias contradictorias y sean decididas en un solo proceso.

\section{Principio de Adquisición Procesal:}

Como lo ha señalado la Jurisprudencia del Tribunal Supremo de Justicia, en Sentencia Nro 70 del 24 de Marzo de 2.000. Sala Casación Civil. Dr Franklin Arrieche: 
"Según el principio de Adquisición Procesal, la autoridad de las partes no determina la conducta del juez en la formación de su convicción acerca del mérito de las pruebas, las cuales se consideran adquiridas para el proceso y no para cada una de las partes individualmente consideradas. Según este principio, una vez incorporada la prueba al proceso, deja de pertenecer al litigante que la ha producido, para transformarse en común, que es la denominada "Comunidad de la Prueba" cada parte puede aprovecharse, indistintamente, de su prueba como la producida por la contraparte, y a su vez, el juez puede utilizar las resultas probatorias aún para fines diferentes de aquellos que contemplan las partes que las producen, de modo que el juez puede valorarlas libremente, conforme a la regla de la sana critica, aún en beneficio del adversario de aquella parte que ha producido la prueba".

Según este principio, todo cuanto se alega y se dice en el proceso, nos perjudica o beneficia por igual. De modo que, todas aquellas afirmaciones que hagamos en el proceso pueden beneficiarnos, pero si alguna de nuestras afirmaciones benefician a la contraparte, ésta puede invocarla a su favor, en virtud de que todo cuanto se diga en el proceso nos perjudica o beneficia por igual. En algunas ocasiones, este Principio de Adquisición Procesal se le ha denominado también De la Comunidad de la Prueba. Sobre este respecto, la antigua Corte Suprema de Justicia ha dicho que para que proceda el Principio de Adquisición Procesal o Comunidad de la Prueba, es necesario que la parte que lo quiera hacer valer, lo haya invocado en el proceso. Por eso es aconsejable y con mucha frecuencia se ve en los escritos de los abogados en estrados, que, cuando ofrecen pruebas, invocan el beneficio que arrojan a su favor las actas y documentos del proceso.

\section{El Principio de publicidad del proceso:}

Se ha dado de dos maneras:

1. Mediante la participación directa del pueblo en el mismo, como existe en aquellos países en el cual las decisiones se dan mediante jurado y en presencia del público.

2. Como en el nuestro, en que todas las personas pueden imponerse de las actas procesales; y de conformidad con el artículo 24 del Código de Procedimiento Civil, los actos del proceso serán públicos pero se procederá a puerta cerrada cuando así lo determine el Tribunal, por motivos de decencia pública, según la naturaleza de la causa. En estos casos, cuando el Tribunal prohibe la publicidad de las actuaciones, ni las partes ni los terceros podrán publicar los actos que se hayan verificado, ni dar cuenta o relación de éllos al público, bajo multa de un mil a cinco mil bolívares, o arresto hasta por 8 días, penas que impondrá el juez por cada falta. También está prohibida la expedición de copias en los juicios de niños y adolescentes en situación irregular. Es de interés privado el estudio del expediente y solicitudes, las conferencias de los jueces y la redacción del fallo, sin perjuicio de la publicación del fallo que se hará posteriormente. 
Según Hernando Devis Echandía (1966: p 49): “ significa este principio que no debe haber justicia secreta, procedimientos ocultos, fallos sin antecedentes ni motivaciones...".

De extraordinaria relevancia se vuelve mencionar que, el 19 de septiembre de 2006, la Corte Interamericana de Derechos Humanos resolvió, en el caso Claude Reyes y Otros vs. Chile un primer pronunciamiento supranacional respecto del derecho de acceso a información pública.

Dicha sentencia, no sólo corrobora aspectos ya sentados por nuestros tribunales en relación con el derecho de acceso a la información, v. gr., en cuanto a la legitimación activa y al peso de la prueba, sino que sustenta ese derecho en la Convención Americana, por lo que su vulneración implica, entonces, lesionar también dicho pacto internacional.

Por otra parte y sin desconocer que la decisión referida admite también reparos, como en lo relativo a la amplitud de la información en poder del Estado que puede ser accedida por las personas, incluye un acápite infraccional de la mayor relevancia para nuestra jurisprudencia, cuyo alcance se extiende mucho más allá del derecho de acceso, en cuanto a la obligación evidente que pesa sobre los tribunales en orden a fundamentar las sentencias, particularmente, tratándose del recurso de protección.

\section{EL Principio de igualdad de las partes:}

Artículo 15 del Código de Procedimiento Civil.

Según Hernando Devis Echandía (1966: p 48):

"Dos consecuencias se deducen: 1 . La de que en el curso del proceso las partes gozan de iguales oportunidades para su defensa, lo cual halla fundamento en la máxima audiatur ex altera parts, y viene a ser una aplicación del postulado que consagra la igualdad de los ciudadanos ante la ley, base de la organización de los Estados modernos; 2. Que no son aceptables los procedimientos privilegiados, al menos en relación con raza, fortuna o nacimiento de personas".

Siendo que nuestro ordenamiento jurídico vigente nos garantiza la igualdad ante la Ley, y así en casi todos los órdenes jurídicos existen, comúnmente, a nivel constitucional, una serie de reglas jurídico-generales que se refieren a la igualdad. Por ejemplo: el llamado principio o garantía de la igualdad ante la ley; la prohibición de las distinciones fundadas en el sexo, la raza, el color, la religión, la condición económica o social, etc. Tales reglas, u otras semejantes, son consagradas positivamente o admitidas suprapositivamente en los diversos órdenes jurídicos del mundo. Por ello, el Artículo 21 de la Constitución del 1.999 consagra este principio de una forma detallada y explícita, en la siguiente forma, tomando en cuenta el artículo 21 de la Carta Magna:

"Artículo 21: Todas las personas son iguales ante la ley, y en consecuencia: 
1. No se permitirán discriminaciones fundadas en la raza, el sexo, el credo, la condición social o aquellas que, en general, tengan por objeto o por resultado anular o menoscabar el reconocimiento, goce o ejercicio en condiciones de igualdad, de los derechos y libertades de toda persona.

2. La ley garantizará las condiciones jurídicas y administrativas para que la igualdad ante la ley sea real y efectiva; adoptará medidas positivas a favor de personas o grupos que puedan ser discriminados, marginados o vulnerables; protegerá especialmente a aquellas personas que por algunas de las condiciones antes especificadas, se encuentren en circunstancias de debilidad manifiesta y sancionará los abusos o maltratos que contra ella se cometan."

Significa que las dos partes, constituidas por el demandante y el demandado o el acusador y el acusado dispongan de las mismas oportunidades para formular cargos y descargos y ejercer los derechos tendientes a demostrarlos.

Es así como, por ejemplo, en un proceso declarativo el demandante formula en la demanda su pretensión y el demandado pronuncia frente a ella dentro del término del traslado que se le corre a continuación de la notificación del auto de admisión. Viene luego el periodo probatorio para practicar las pruebas solicitadas por las partes en la demanda y su contestación.

La noción de igualdad jurídica constituye una de las nociones jurídicas más íntimamente vinculadas con los cambios histórico-sociales, pudiéndose decir, por ello, que es una noción evolutiva. Así su significación abstracta, que le viene dada por su consagración legislativa, como su significación concreta que es precisada por la interpretación jurisprudencial depende de las estructuras políticas, jurídicas, económicas y sociales (comprendiendo aquí las estructuras religiosas, morales, étnicas y de estratificación social) existentes en la colectividad y de los valores socialmente aceptados en una época dada. Por esto es posible afirmar que las normas jurídicas que establecen una desigualdad o, por el contrario, suprimen una y proclaman una determinada igualdad, son la expresión: o bien de una desigualdad social, o bien de una reacción debida al cambio de las valoraciones sociales, que a su vez el resultado, en gran parte de una transformación de las estructuras colectivas.

Así, pues, cuando en una comunidad dada se piensa por la mayoría de sus integrantes, o al menos por las clases o grupos sociales que aspiran al control del poder en la misma, que una determinada igualdad jurídica y/o social hasta ese momento aceptada, o al menos, soportada, se les debe suprimir por sentírsela como injusta, se inicia un proceso de lucha social tendiente a cambiar las estructuras de dicha comunidad que hacen posible aquella desigualdad. Pues como ya dijo ARISTÓTELES, la desigualdad es siempre la causa de las revoluciones, cuando no tienen ninguna compensación los que son victimas de ella... y en general puede decirse que las revoluciones se hacen para conquistar la igualdad. 
Ello significa, entonces, que nuevos valores se hacen predominantes en la colectividad. Empero, es necesario indicar que este cambio axiológico es causa y efecto de las transformaciones de las estructuras de la sociedad. Es decir, que si se tiene como injusta una determinada desigualdad jurídica y/o social y la estructura que la fundamenta, es porque los valores que la hacían soportable han cambiado. Pero esto implica, a su vez, el cambio, al menos, de una estructura.

Así la transformación de una estructura económica o religiosa, por ejemplo, pueden hacer cambiar las valoraciones populares en vigor y hacer sentir las estructuras políticas y jurídicas, como injustas y viceversa.

Según el autor Adolfo Gelsi Bidart, citado por Petzold ( 1994: p 451) la "igualdad en el proceso, significa posibilitar a cada parte para que haga valer sus derechos ante el Juez, rodearla de las garantías y quitar los obstáculos para que libremente pueda alegar en el ataque o en la defensa y aportar los medios de convencimiento necesarios."

Por ello, es que debemos buscar siempre la igualdad, ya que, según Petzold (1974: p 66): “...en la actualidad y en la gran mayoría de las naciones civilizadas, como lo señala también el jurista inglés H.L.A. HART se acepta " el principio de que prima facie los seres humanos tienen derecho a ser tratados con igualdad...."

Continúa el mencionado autor (1974: p 68):

"De ahí que la utilización de determinados criterios de relevancia, como la consideración de ciertas personas como iguales o desiguales jurídicamente, son cuestiones esencialmente axiológicas, pues implican la formulación de juicios de valor por medio de actos de voluntad de carácter jurídico, a los cuales sirven de vehículo de sentido las normas de una constitución, una ley, un reglamento, una sentencia, etc., en fin, normas jurídicas generales o individualizadas, según los casos".

Se debe tomar en cuenta, que en la mayoría de las legislaciones modernas, incluyendo la Venezolana hasta 1.999, la Justicia Gratuita es un beneficio que se aplica como una excepción a la regla general, donde la exoneración de los gastos judiciales se concede sólo a los legal o judicialmente declarados "pobres".

Es por esto, que luego de la entrada en vigencia de la Constitución de la República Bolivariana de Venezuela en 1.999, donde el constituyente Venezolano en un propósito innovador, rompió con la uniformidad que había con respecto a éste principio, al establecerlo ahora como un principio de carácter general.

De lo anteriormente escrito, podemos ver que lo que establece el Código de Procedimiento Civil en cuanto al citado principio quedó derogado, ya que la Constitución buscando la igualdad jurídica de las partes en el proceso y elevando la justicia al rango de derecho social, ha implementado el beneficio de la justicia gratuita, no como un beneficio de pobreza, sino como un beneficio general para acceder a la justicia en Venezuela. Para ello la Constitución establece en el Artículo 26: ..."El Estado garantizará una justicia gratuita, accesible, imparcial, 
idónea, transparente, autónoma, independiente, responsable, equitativa y expedita, sin dilaciones indebidas, sin formalismos o reposiciones inútiles". En concordancia con lo que establece el artículo 254 de la Constitución, donde dice que "...el Poder Judicial no está facultado para establecer tasas, aranceles, ni exigir pago alguno por sus servicios".

De esta manera vemos como la evolución de las valoraciones admitidas -que influyen socialmente y que son interpretadas por los cambios de las condiciones de vida de un país, se reflejan en las condiciones jurídicas y sociales de la población, respecto a la noción de igualdad no uniforme, todo basado en la imposición social.

Como lo afirma Petzold (1974: pp 75, 76)

"En dicha lucha social, los jueces desempeñan un gran rol, ya sea que adopten una actitud revolucionaria (o al menos reformista), es decir, a favor de la nueva regla de igualdad, ya sea que integren al partido de los conservadores y estén en contra de dicha regla, y a favor de la desigualdad social y/o jurídica que se trata de suprimir manifestándose su posición al respecto, o bien por fallos tendientes a darle vigencia, es decir, eficacia a las normas jurídicas generales que consagran la nueva regla de igualdad, mediante su efectiva aplicación a los casos concretos; o bien, por decisiones que, negándoles a esas normas su vigencia, proclaman el mantenimiento de la desigualdad que las mismas pretenden erradicar.

Entonces, lo expuesto explicaría la presencia, en Venezuela y otros países de América Latina, de numerosas normas jurídicas generales, casi siempre de carácter constitucional, que no son más que normas-fachada debido a una aplicación judicial conservadora o a una absoluta falta de aplicación, que, en vez de contribuir a eliminar algunas de las graves desigualdades sociales y jurídicas existentes, sirven por el contrario, para dar buena conciencia a los privilegios del "statu quo" y a disimular ante la opinión pública internacional, y hasta nacional, violaciones de la dignidad humana".

El sentido de las normas jurídicas generales que establecen una regla de igualdad, se ve afianzado por la interpretación de los jueces $u$ otros funcionarios encargados de aplicarlas concretamente, por lo que la vigencia y aplicación de tales normas depende de sus creencias, concepciones e intereses, y bajo la influencia de lo que un determinado ambiente histórico-social les den.

Sin embargo, no hay duda de que las intenciones que se han tenido al establecer este principio de forma general sean buenas, ya que según Fairen Guillén (1990) se trata de un potente instrumento para crear la igualdad de condiciones a los fines de persecución del derecho concedido a los círculos de población que tengan menos medios; ya que sino de algún modo con respecto a ellas habría una verdadera e inicua denegación de justicia; y por ello se quiso sopesar o equilibrar esta situación.

Sobre todo, la disposición citada de la Constitución trata de mantener la igualdad 
entre las partes; proponiendo a tal fin, la supresión de los obstáculos económicos que dificultan el acceso a la justicia.

\section{El Principio de Lealtad y Probidad y Veracidad:}

Artículos 17, 170 y 171 del Código de Procedimiento Civil.

Probidad, significa integridad, honestidad, rectitud en el proceder y honradez. Contribuye a realzar las cualidades morales y profesionales del abogado. El principio de probidad enseña que el proceso es un debate en el cual debe actuarse de buena fe.

Por su parte Lealtad, significa actuar honorable y fielmente, actuar con legalidad y con veracidad, fidelidad y cumplimiento sin reservas una obligación o un pacto demostrando buena fe y rectitud en el proceder.

La moralización del proceso es un fin perseguido por todas las legislaciones como medio indispensable para la recta administración de justicia.

La lealtad y probidad procesales son consecuencia de la buena fe en el proceso, y excluye las trampas judiciales, los recursos torcidos, la prueba deformada y las inmoralidades de todo orden.

La lealtad y la probidad tiene una relación directa con la igualdad de las partes, puesto que un acto desleal, obrar de mala fe o una falta de probidad pueden desestabilizar la igualdad procesal y enervar el principio de la igualdad de las partes en el proceso. En este sentido es conveniente hacer mención a la práctica del derecho, ya que en esta profesión la probidad y la lealtad requieren de mejor aplicación. La profesión de abogado es una tarea de apostolado a la cual debe rendirle culto el profesional del derecho siendo probo, procediendo con rectitud de ánimo, integridad personal y honradez. La actitud debe responder a la verdad y a los dictados de la conciencia, siendo responsable por los daños y perjuicios de quienes actúen con temeridad o mala fe.

Según Hernando Devis Echandía (1966: p 65): "La ley procesal debe sancionar la mala fe de las partes o de sus apoderados, estableciendo para ello severas medidas. Consecuencia del principio que estudiamos es la obligación de las partes de decir la verdad en la demanda y en su contestación principalmente, pero, en general, en todo el curso del proceso".

La bilateralidad inherente a todo proceso judicial exige el establecimiento de parámetros que señalen las diferentes cargas que deben asumir los litigantes en sus actividades de petición y defensa. Adicional a esto existen deberes recíprocos orientados a la obtención de un debate limpio en igualdad de condiciones. Este principio de lealtad y probidad adquiere mayor fuerza e importancia al reafirmarse el carácter público del proceso.

En nuestro Código de Procedimiento Civil el legislador trata de erradicar del proceso las maniobras desleales estableciendo en su Artículo 17 el deber del juez 
de tomar de oficio o a petición de parte todas las medidas necesarias establecidas en la ley, tendentes a prevenir o a sancionar las faltas a la lealtad y probidad en el proceso, las contrarias a la ética profesional, la colusión y el fraude procesales o cualquier acto contrario a la majestad de la justicia y al respeto que se deben los litigantes.

Así mismo mediante el Artículo 170 ejusdem crea en las partes el deber de veracidad para alcanzar el objetivo de un proceso leal además de sencillo y expedito en interés de la colectividad instaurando la posibilidad de una condena para el litigante malicioso al prever la responsabilidad civil por los daños y perjuicios que causen las partes o los terceros que actúen con temeridad o mala fe y mediante la consagración de la presunción iuris tantum de la temeridad o mala fe procesales de quienes deduzcan en el proceso pretensiones o defensas, principales $o$ incidentales infundadas; alteren $u$ omitan hechos esenciales a la causa y obstaculicen ostensible y reiteradamente el desenvolvimiento normal del proceso. Se creó así mismo la responsabilidad extracontractual objetiva por la malicia procesal de las partes o de sus apoderados, como un tipo de condena al dolo o culpa cometidos en el proceso, es decir, como sanción civil a la falta de probidad procesal. Se puede ubicar la fuente de esta responsabilidad en el llamado "abuso de derecho", modalidad del derecho ilícito que obliga a reparar el daño causado a otro, por quien bajo el pretexto de ejercer un derecho subjetivo, excede en ese ejercicio, los límites fijados por la buena fe o por el objeto en virtud del cual se le ha conferido ese derecho. Sin embargo el supra citado código no solo establece responsabilidades y sanciones para los actos de deslealtad en el proceso, sino que siguiendo la máxima de prevenir antes que castigar dicta una serie de medidas tendentes a impedir esas anomalías. En este sentido el legislador al consagrar positivamente el principio de lealtad procesal, le ha dado una nueva perspectiva al aspecto ético - social del proceso, en un claro reconocimiento de que se trata de un instrumento que busca conciliar la libertad con la justicia.

La moralidad y la probidad han sido expresamente consagradas al mismo tiempo que están presentes en toda la duración del proceso civil y son estos principios fundamentales los que el legislador ha considerado necesarios incorporar al sistema para dar mayor pulcritud al régimen procesal, ya que como bien lo señala Couture (1976), son las infinitas posibilidades de dilación que el proceso depara las que instan al litigante de escasos escrúpulos a poner tiempo y fatiga de por medio, a fin de evitar o prolongar su necesaria derrota. Abreviado y simplificado el procedimiento, determinados con precisión los poderes del magistrado para contener al litigante malicioso y acentuadas las responsabilidades del mismo y de su abogado, el problema del litigante malicioso podría disminuir de entidad.

Tanto en la venezolana como en otras legislaciones la obligación de veracidad ha evolucionado hacia la obligación genérica de no litigar de mala fe, la cual se refiere principalmente al resultado final del proceso y que se limita a exigir en el litigante la convicción de tener la razón. 


\section{CONCLUSIONES}

1.- El problema de la delimitación de una teoría unitaria del Derecho Procesal ha atravesado por un largo proceso histórico que tuvo sus inicios en la primera mitad del siglo XX y que coincide con el surgimiento del Derecho Procesal como ciencia.

2.- La oposición a la concepción unitaria del Derecho Procesal ha venido siempre desde el campo del Derecho Penal, argumentando que existen hondas diferencias entre el Procesal Civil y el Procesal Penal que tienen que ver sobre todo con la naturaleza de las normas de derecho sustantivo que se aplican en cada caso y con la finalidad de ambos modelos con respecto a la prueba en función de la búsqueda de la verdad.

3.- El valor del análisis unitario está en que las herramientas conceptuales que se utilicen para su análisis permitan una sistematización uniforme.

4.- Las categorías que conforman la trilogía estructural del Derecho Procesal sobre las que se eleva la teoría unitaria son tres: acción, jurisdicción y proceso.

5.- En la actualidad existe una amplia gama de clasificaciones de los principios del Derecho Procesal las que difieren en cuanto a los criterios de ubicación y denominación.

6.- Existen en el Derecho Procesal principios que tienen elementos comunes en unos y otros procesos, los que conforman un sistema de conocimientos que permiten, junto a la trilogía estructural del Derecho Procesal, fundamentar la concepción unitaria del mismo en nuestro país.

\section{RECOMENDACIONES}

1.- Continuar con el estudio de este tema por ser muy novedoso sobre todo en América Latina, además por su importancia para la enseñanza del Derecho procesal en el siglo XXI.

2.- Que el presente trabajo investigativo, aunque no es una obra concluida, sirva de material de estudio sobre el tema porque actualmente la bibliografía al respecto es escasa.

3.- Que a partir de este momento en la impartición de las asignaturas Derecho Procesal Civil y Derecho Procesal Penal, siempre que sea posible, los profesores inserten el tema de la teoría unitaria del Derecho Procesal para que los estudiantes se vayan familiarizando y comprendan el mismo. 
4.- Que este tema sea abordado en los cursos de superación postgraduada para los juristas en el ejercicio de la profesión.

\section{BIBLIOGRAFÍA}

Alsina, H. (1956). Tratado Teórico-Práctico de Derecho Procesal Civil y Comercial. Ediar Editores, Buenos Aires.

Alsina, H. (1962). Tratado Teórico-Práctico de Derecho Procesal Civil y Comercial. Ediar Editores, Buenos Aires.

Arias, H. (1999). La Competencia. Monografía. Ula. Mérida.

Balzan. J. (1985). Lecciones de Derecho Procesal Civil. Editorial Sulibro. Caracas. BORJAS, Arminio. (1979) Comentarios al Código de Procedimiento Civil Venezolano. Edición Librería Piñango. Caracas.

Briseño, H. (1995). Derecho Procesal. Segunda Edición. Harla. México

Borjas, A. (1979) Comentarios Al Código De Procedimiento Civil Venezolano. Edición Librería Piñango. Caracas.

BULLOW, O (1964). La teoría de las excepciones procesales y los presupuestos procesales. / O. Bullow. Alemania: Ediciones Jurídicas.

Cabanellas. Guillermo. (1979). Diccionario Enciclopédico De Derecho Usual. Tomo H. Editorial Heliasta S.R.L. Buenos Aires.

Calvo Baca, Emilio. (1997). Código de Procedimiento Civil, de Venezuela Edición con anexos y comentarios a la reforma. Ediciones Libra. Caracas.

Capitan, H. (1964). Metodología De La Investigación Jurídica. Editorial Díaz De Santo. Madrid.

Carnelutti, F. (1956). Sistema De Derecho Procesal Civil. Tomo I, Ii, Iii. Uthea Editorial. Buenos Aires. 
.- (1959). Instituciones Del Proceso Civil. Ejea. Buenos Aires.

Chiovenda, G. (1922). Instituciones de Derecho Procesal Civil. Editorial Revista de Derecho Privado.

Corte Interamericana de Derechos Humanos. Sentencia de fecha 19 de septiembre de 2006. Caso Claude Reyes y Otros vs. Chile.

Couture, E. (1978). Fundamentos del Derecho Procesal Civil. Ediciones De palma. Buenos Aires.

.- (1979). Vocabulario Jurídico. Ediciones Desalma. Buenos Aires.

Cuenca, H. (1974). Derecho Procesal Civil. Tomo I. Ediciones De La Biblioteca. Caracas.

Devis E, H. (1985). Compendio de Derecho Procesal .Tomo I. Décima Edición. Editorial ABC. Bogotá.

.- (1966). Nociones Generales de Derecho Procesal Civil. Aguilar S.A. de Ediciones. Madrid.

Díaz, A. (1972). Instituciones de Derecho Procesal. Edit. Abeledo-Perroy. Buenos Aires.

Enrique, L. (1998). Manual de Derecho Procesal Civil. Abeledo-Perrot. Argentina.

Fairen Guillen, Víctor (1990). Doctrina General del Derecho Procesal, Barcelona, edit. Librería Bosch.

Guasp, J. (1977). Derecho Procesal Civil. Instituto de Estudios Políticos, Madrid.

Hernández, A. (1963). Código de Procedimiento Civil Venezolano. Quinta Edición con institulación y Anotaciones a su articulado. Editorial La Torre. Caracas.

Quintero, B. Prieto, E. (1992). Teoría General del Proceso. Editorial Temis. Bogota.

Manzini, V. (1979). Tratado de Derecho Procesal. Buenos Aires.

Mattirolo, L. (1930). Tratado de Derecho Judicial Civil. Quinta edición. Editorial Reus. Madrid.

Palacio, Lino Enrique (1968). Manual de Derecho Procesal Civil. Abelledo- Perrot. Buenos Aires.

Perdomo. C. (1999). La Jurisdicción y la Competencia. Monografía. UCV. Caracas.

Petzold Pernia, Hermann (1974). La Noción de Igualdad en el Derecho de Algunos Estados de América Latina. Maracaibo. Edit. Centro de Estudios de Filosofía del Derecho.

Pineda León. P. (1980). Lecciones elementales de Derecho Procesal Civil. Observaciones al Nuevo Proyecto del Código de Procedimiento Civil. Tomo I. Cuarta Edición. Talleres Gráficos Universitarios, Mérida. 
Podetti, R. (1956). Derecho Procesal Civil, Comercial y Laboral. Ediar Editores. Buenos Aires.

Redenti. E. (1957). Derecho Procesal Civil. Tomo III. Ediciones Jurídicas de Europa-América. Buenos Aires.

Rengel Romber, A. (1992). Manual de Derecho Procesal Civil Venezolano. Volumen I. Prensas Venezolanas de Editorial Arte. Caracas.

Rocco, U. (1983). Tratado de Derecho Procesal Civil. Editorial Temis-Depalma. Bogotá.

Tribunal Supremo de Justicia. Sala Constitucional. Sentencia de fecha 07 de agosto de 2003, Exp.02-2403, con ponencia del Magistrado José Manual Delgado Ocando.

Tribunal Supremo de Justicia. Sentencia Nro 70 del 24 de Marzo de 2.000. Sala Casación Civil. Dr Franklin Arrieche.

Universidad Pedagógica Experimental Libertador. (1998). Manual de Trabajos de Grado de Especialización y Maestría y Tesis Doctorales. Vicerrectorado de Investigación y Postgrado. Venezuela.

Véscovi, E. (1999). Teoría General del Proceso, Segunda edición, Editorial Temis S.A. Bogota.

Villasmil, F. (1982). Los Principios Fundamentales y las Cuestiones Previas en el Nuevo Código de Procedimiento Civil. Tomo I. Maracaibo.

Satta, Salvatore. Manual de Derecho Procesal Civil. Ediciones Jurídicas Europa América. Buenos Aires. 1971.

Zoppi, A. (1990). Soluciones a Errores en el Código de Procedimiento Civil. Editores Hermanos Vadell. Caracas. 1990. 